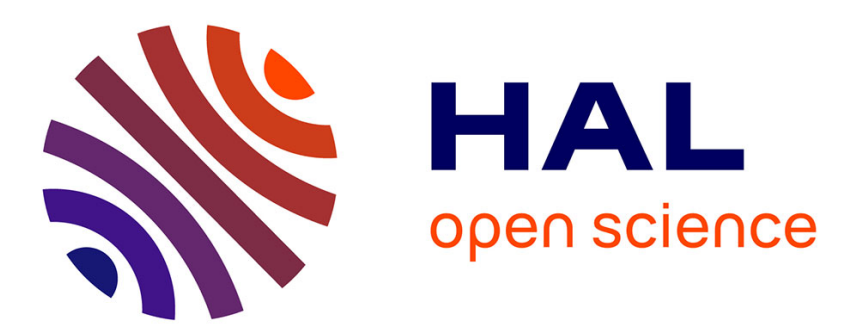

\title{
A new higher education curriculum in organic chemistry: what questions should be asked?
}

David Lafarge, Ludovic Morge, Martine Méheut

\section{To cite this version:}

David Lafarge, Ludovic Morge, Martine Méheut. A new higher education curriculum in organic chemistry: what questions should be asked ?. Journal of Chemical Education, 2014, 91 (2), pp.173178. 10.1021/ed300746e . hal-00936602

\section{HAL Id: hal-00936602 https://hal.science/hal-00936602}

Submitted on 19 Feb 2020

HAL is a multi-disciplinary open access archive for the deposit and dissemination of scientific research documents, whether they are published or not. The documents may come from teaching and research institutions in France or abroad, or from public or private research centers.
L'archive ouverte pluridisciplinaire HAL, est destinée au dépôt et à la diffusion de documents scientifiques de niveau recherche, publiés ou non, émanant des établissements d'enseignement et de recherche français ou étrangers, des laboratoires publics ou privés. 


\section{Title of the manuscript}

A new higher education curriculum in organic chemistry: what questions should be asked?

\section{Authors' names and affiliations}

\section{David L. Lafarge*}

Associate professor: Clermont Université - Université Blaise Pascal - IUFM d'Auvergne, 36 avenue Jean Jaurès, C.S.20001, F-63407 CHAMALIERES Cedex, FRANCE.

Doctor, member of the ACTé research laboratory - Clermont Université - Université Blaise Pascal - IUFM d'Auvergne, 36 avenue Jean Jaurès, C.S.20001, F-63407 CHAMALIERES Cedex, FRANCE.

david.lafarge.ubp@gmail.com

\section{Ludovic M. Morge}

Professor: Clermont Université - Université Blaise Pascal - IUFM d'Auvergne, 36 avenue Jean Jaurès, C.S.20001, F-63407 CHAMALIERES Cedex, FRANCE.

Member of the ACTé research laboratory - Clermont Université - Université Blaise Pascal IUFM d'Auvergne, 36 avenue Jean Jaurès, C.S.20001, F-63407 CHAMALIERES Cedex, FRANCE.

Ludovic.Morge@univ-bpclermont.fr

\section{Martine M. Méheut}

Professor emeritus: Université Paris-Est - Créteil Val-de-Marne , 61 avenue du Général de Gaulle, F-94010 CRETEIL Cedex, FRANCE.

Member of the Laboratoire de Didactique André Revuz research laboratory - Université Diderot-Paris 7, 10 rue Alice Domon et Léonie Duquet, F-75205 PARIS Cedex 13, FRANCE.

Martine.Meheut@univ-paris-diderot.fr

\section{Abstract}

Organic chemistry is often considered to be a difficult subject to teach and to learn, particularly as students prefer to resort to memorization alone rather than reasoning using models from chemical reactivity. Existing studies have led us to suggest principles for redefining the curriculum, ranging from its overall structure to the tasks given to the students. We suggest reorganizing the contents around the organic chemist's questions and even in the first year implementing teaching based on modeling, organic synthesis and using a database (the 'reaction library') in class. Finally, we present a full curriculum reconciling these principles with the current contents of an organic chemistry course.

\section{Keywords}

Keywords (Audience): First-Year Undergraduate / General, Second-Year Undergraduate, High-School / Introductory Chemistry

Keywords (Domain): Chemical Education Research, Curriculum, Organic Chemistry Keywords (Pedagogy): Problem Solving / Decision Making

Keywords (Topic): Enrichment / Review Materials, Mechanisms of Reactions, Synthesis 


\title{
A new higher education curriculum in organic chemistry: what questions should be asked?
}

\author{
David Lafarge*, Ludovic Morge \\ Clermont Université, Université Blaise Pascal, EA4281, Laboratoire ACTé, BP 10448, F- \\ 63000, CLERMONT-FERRAND, FRANCE ; \\ *david.lafarge.ubp@gmail.com ; \\ Martine Méheut \\ Université Paris-Est - Créteil Val-de-Marne, Laboratoire de Didactique André Revuz, \\ Université Diderot-Paris 7, F-75205 PARIS Cedex 13, FRANCE
}

\begin{abstract}
Organic chemistry, as it is taught in the first two undergraduate years, is reputed to be difficult $^{1}$ even for students coming from the best universities. ${ }^{2}$ Many suggestions - in this journal more often than not - have been made for improving the teaching of organic chemistry. The first we can mention involves improving implementation without making any fundamental changes to the structure and contents of the course. This can be done by, for example, using different aids ${ }^{3-7}$ or the collaborative learning approach and problem-solving activities. ${ }^{2,4,9-21}$ The second suggestion aims to redefine the course content itself both in the way it is organized, and in its priorities: the content of the course could be made lighter, teaching highly complex notions could be put off and applications updated ${ }^{22-25}$, the strategy for organic synthesis could be tackled sooner ${ }^{17,26,44}$, symbolism could receive special attention $^{27-31}$, and the curriculum could generally be reorganized using a spiral (or 'two-cycle') approach $^{32-35}$, or using reaction mechanisms and models. ${ }^{36-44}$
\end{abstract}

This article was written with this second perspective in mind, and aims at improving the teaching and learning of organic chemistry in the first two years of higher education courses in France. First, we will show the difficulties and contradictions in the way the subject is currently taught, building on existing studies (including ours). We will then suggest some principles for redefining the curriculum. Finally, we will present a complete curriculum reconciling these principles with the current contents of the organic chemistry course during the first years in higher education.

\section{A curriculum organized around functional groups}

Johnson ${ }^{45}$ studied the way in which organic chemistry is taught in thirty-three American universities and colleges and showed that the curriculum in most cases is organized around functional groups. The textbooks for the courses are organized in the same way. This is also true in France. ${ }^{44}$ This organization is rooted in the history of the subject, as can be seen in the changes in chemistry books since the $19^{\text {th }}$ century. ${ }^{46}$ In 1845 , the French chemist, Charles Gerhardt gave a classification of organic substances according to their chemical function.

Books published after this date use this classification when organizing their contents, without making any significant change in spite of two fundamental epistemological changes described by Loumouamou. ${ }^{47}$ Lewis theory, at the start of the $20^{\text {th }}$ century is the first of these. A consideration of the reaction medium completes the electronic approach, integrating 'socio-molecular phenomena' in the analysis of reactivity. Quantum mechanics is the second change in relation to the mode of reasoning coming from Lewis theory.

Professors have little lee-way with this organization of content which is rooted in the history of their subject, and currently prevalent in most text-books and courses in the first years in higher education. We think that professors, by using this content organization have 'developed a conceptual structure in which knowledge of the subject, as well as of teaching, learning and pupils is organized in a coherent way' (p.166) ${ }^{48}$ and this coherence convinces 
them that this organization is relevant. ${ }^{44}$ But is it really as relevant as they think when it comes to learning processes? There would seem to be a link between the structure and the difficulty of the subject. ${ }^{21,40}$

Many publications report that students find this subject difficult, thinking they have to resort to memorization in order to pass their exams and that they are unable to reason using reaction models. Couldn't this be due to the organization of the curriculum around functional groups, which was devised a long time ago to describe and classify reactions in organic chemistry, when current theoretical models did not yet exist?

\section{Does the current curriculum allow students to reason rather than to memorize?}

Publications often refer to the importance for organic chemistry students of memorizing content. Loumouamou shows that there is a discrepancy between students and professors in this field ${ }^{47}$ : students consider it is more effective to take refuge in memorizing to get good results, whereas professors consider it better to reason, using models. American studies have shown that most students, when they solve problems, resort to sequences of stages they have memorized, and they rebuild the puzzle with these. They have only retained the underlying concepts and models as mere words with no meaning. ${ }^{41,49}$ Students may also devise surprising strategies, such as connecting the choice of the way reactants are represented (relative position of reactants, 2D or 3D) with the reaction which occurs, taking no account of its characteristics. ${ }^{50,51}$

Why do students resort to alternative strategies rather than a strategy based on reasoning using organic chemistry models? Is it because it is harder to use models? Indeed, problem-solving by experts in organic chemistry necessitates using different intertwined models. ${ }^{44,47}$ Are the models truly operational $?^{41}$ It may not be the nature of the models which is problematic, but rather the tasks given to the students. Can these tasks be carried out through reasoning using models, or only through memorization?

One answer can be found in the analysis of 375 tasks from exam subjects in France, all dealing with reactivity and reactions in organic chemistry ${ }^{44}$. It would seem that it is not possible to complete the tasks successfully by only using a modeling strategy: the goals of the tasks (for example, predicting the final product, or devising a reaction mechanism) cannot be achieved only with models, if only the structure of the reactants is known. All the conditions necessary for carrying out the tasks are not present (the students do not have the data which are indispensable for the models to work, such as thermodynamic data, etc.). It is therefore more effective, for students to be able to answer the question, to resort to a memorization strategy. This consists in recognizing the nature of the reactants and using a reaction or a mechanism they have already memorized. The study reveals a link between the way the curriculum is structured and the strategies for carrying out the tasks which have already been analyzed: organizing the curriculum around functional groups leads students to use memorization strategies and not modeling strategies.

The discrepancy which Loumouamou noticed between students and professors in relation to doing well in organic chemistry ${ }^{47}$ thus seems to be the result of a form of misunderstanding between them. With the curriculum as it is generally structured today, professors who have a contemporary vision of organic chemistry, believe they are enabling students to use models. But in fact, students have no choice but to resort to an older and descriptive form of organic chemistry which entails memorizing reactions and their characteristics.

\section{Why propose a new curriculum?}

Modeling is the core of scientific activity, and therefore the core of science teaching too. ${ }^{52}$ However, when Loumouamou suggested a teaching sequence on modeling a reaction 
mechanism close to present reference knowledge, the attempt was not conclusive as it was taught with a different logic from the rest of the course. ${ }^{47}$ The analysis of the tasks given to the students showed that the current curriculum and the very nature of the tasks led students to apply a memorization strategy, and not a modeling strategy. ${ }^{44}$ It is thus essential to reshape the curriculum entirely so that the organic chemistry which students are taught is consistent with the nature of this science, and so that they can manage the tasks by using models. ${ }^{44,53-59}$

The main object of organic chemistry today is not an exhaustive description and a classification of known reactions. This is why a curriculum whose aim is to teach reactions is no longer appropriate. We should note that proposals for a spiral approach or an approach by type of reactions/mechanisms are also focused on the description of reactions which they organize and present in a different way. The great rise in the number of reactions in organic chemistry means that the amount of content to be taught is continually increasing. Will it be possible to continue adding to the curriculum in this way? The answer is obviously no. So how can we choose which reactions to keep and which to take out? This question should not have to be asked. What we need to do is to redirect the curriculum towards the current objectives of organic chemistry.

If we take a look at the table of contents in the latest issues of The Journal of Organic Chemistry, we can get a good idea of the current state of the discipline. The articles are very varied, dealing with the synthesis of chemical species, the study of parameters and the improving of important reactions in organic synthesis, the study of reaction mechanisms, and the perfecting of techniques adapted to problems in organic chemistry, etc. Organic synthesis, which is seen both as a science and an art, is one of the main finalities in professions related to organic chemistry. ${ }^{60}$ We share Taagepera and Noori's opinion that the learning goals for an introductory course in organic chemistry should be for students to be able to recognize structure-reactivity relationships, solve simple synthesis problems, and propose syntheses and the relevant mechanisms for simple cases. ${ }^{40}$

\section{What should be the principles for a new curriculum?}

As a result of existing research and our own findings, we should like to suggest some guiding principles for reshaping the organic chemistry curriculum in the first years in higher education. We have given numbers to present these principles (P1, P2...) so that it will be clearer when they are used.

\section{P1: Reshape the curriculum in relation to the organic chemist's questions}

A theoretical model does not exist for its own sake. It serves to interpret an experimental field ${ }^{61}$ which is the object of our questioning. ${ }^{62}$ Thus, it can provide some elements to help answer some of the questions a scientist asks himself. This is why we propose an overall restructuring of the curriculum based on the questions an organic chemist may ask himself. For example: how can we isolate and identify an organic species? How can we combine available chemical species and known reactions in order to make a target molecule? How can we choose the most effective strategy for organic synthesis? How can we improve the effectiveness of a reaction? How can we select one reaction path rather than another? In the curriculum we propose, the questions and answers are grouped together around some poles, which are organized so that models, reaction mechanisms and organic synthesis can be taught gradually. The progressivity of the curriculum is no longer explicitly based on the increasing complexity of molecular structure, but on the increasing complexity of the chemist's questions and answers.

\section{P2: Encourage students to use modeling}

The way the contents are structured means that only a few simple theoretical models are needed to answer the first questions. The possibilities these models have for interpreting 
or predicting are limited, but sufficient to answer the first questions asked. However the following questions require using more complex models. Thus, we show students that models can evolve, and are only relevant for certain problems in certain contexts. ${ }^{63}$

We give suggestions of new tasks for the students. Their goals have been redefined and diversified, with more data interpretations and accessible predictions. The conditions for carrying out these tasks are provided: experimental findings to be interpreted, and the data necessary for the models to work (electronegativity table, thermodynamic data, etc.). In order to make the models taught easier to use, we also add if necessary other theoretical elements like some of the cross-checks and rules presented by Scudder (the $\Delta \mathrm{pKa}$ rule, etc.). ${ }^{42}$

\section{P3: Encourage the learning of organic synthesis}

Strategy for organic synthesis and retrosynthesis are important aspects of organic chemistry and should be taught in the first year. Some parts of the curriculum are specifically devoted to these questions. However we are not suggesting that this should be limited to tasks simply applying generic reactions that have been memorized, or just transferring a master's course on retrosynthesis to the first year of a higher education course. New tasks are devised for the students in order to tackle the question at this lower level. However, it may be useful to be familiar with some functional group and structure modifications that can be used in organic synthesis: for example, $\mathrm{Smith}^{26}$ has selected about thirty reactions (functional group exchange and carbon-carbon bond forming reactions).

\section{P4: Use a database: the "reaction library"}

Organic chemists use databases when thinking up organic syntheses. We propose already using a database called a reaction library in the first year of higher education. The reaction library is a catalogue of all the reactions students will need for the first years of their course. The reactions have been taken from publications in organic chemistry, and each one is presented using a specific example, with the yield and the bibliographical reference for the article. The reaction library is descriptive, and can thus be structured by functional groups (both the transformed and the formed groups). It shows students where reference knowledge in organic chemistry comes from, and the limits of using reactions outside their original context when solving new problems. Using the reaction library would no doubt facilitate the learning of some reactions in organic chemistry. However, it was not devised with a view to its being memorized for an exam. Therefore, the existence of the reaction library should incite professors and designers of exam papers to present students with new tasks on organic synthesis.

\section{How can these principles be applied in the building of a new curriculum?}

We have tried to reconcile the principles which we have just presented with the current contents of the organic chemistry course. The curriculum as it now stands is structured around 6 broad questions, each of which is broken down into 2 or 3 questions linked with some elements to be used for the answers (P1). The detailed description of the contents is given in the tables, which make the distinction between the "Experimental field" 63 which the questions are about, and the "Notions" which provide some answers (P2). This curriculum is intended for the first two or even three years in higher education. However, we do not indicate a specific amount of time to be spent on each part, as all courses are not the same length everywhere. 


\section{Part 1. How can chemical species be separated and identified? Relationships between structure and physical properties}

This first part (table 1) allows students to gain better knowledge of organic species before they move on to considering the transformations of these in the following parts. The basis of this part is the relationship between the structure of chemical species and their physical properties (P2). We therefore have an opportunity here to make a link with certain experimental techniques associated with the teaching of organic chemistry. Nevertheless, in order to answer the question, there is no need to teach the theoretical principle of these techniques (like spectroscopic techniques for example) in detail (P1). The study of polar covalent bonds and the polarizability of electron clouds makes it possible to explain some socio-molecular aspects (the model of intermolecular forces) and to prepare the ground for studying reactivity in Part 3 (P1, P2).

Table 1. Content description for part 1 of the curriculum

\begin{tabular}{|l|l|}
\hline $\begin{array}{l}\text { How can the structure of an organic species be } \\
\text { determined? }\end{array}$ \\
\hline $\begin{array}{l}\text { Experimental } \\
\text { field }\end{array}$ & $\begin{array}{l}\text { Experimental approach to spectroscopic } \\
\text { analyses of organic species (NMR, IR, UV- } \\
\text { vis, MS); examples of the qualitative influence } \\
\text { of the medium. }\end{array}$ \\
\hline Notions & $\begin{array}{l}\text { Relationships between spectroscopic } \\
\text { properties and the structure of organic } \\
\text { species. Covalent bond, Lewis structures, } \\
\text { resonance. Isomerism, functional groups. } \\
\text { Nomenclature. }\end{array}$ \\
\hline How can an organic species be isolated and identified? \\
\hline $\begin{array}{l}\text { Experimental } \\
\text { field }\end{array}$ & $\begin{array}{l}\text { Measures of melting and boiling points, } \\
\text { refractive index, density. Solvent extraction } \\
\text { and salting out. Chromatography. }\end{array}$ \\
\hline Notions & $\begin{array}{l}\text { Model of intermolecular forces (polar covalent } \\
\text { bonds, polarizability, van der Waals forces, } \\
\text { hydrogen bond) to explain and predict the } \\
\text { differences in organic species' physical } \\
\text { properties. }\end{array}$ \\
\hline
\end{tabular}

\section{Part 2. What is a strategy for organic synthesis?}

This part of the curriculum tackles strategy for synthesis for the first time (P3). Its aim is to describe strategy for organic synthesis and devise simple syntheses by using a database (table 2) (P4). Simply taking reactions from the reaction library shows its limits when more complex syntheses are considered. In this case, it is necessary to have a better understanding of what actually happens in chemical reactions (P1). This will be tackled in Part 3.

Table 2. Content description for part 2 of the curriculum

How can we choose the best strategy for organic synthesis? 


\begin{tabular}{|l|l|}
\hline $\begin{array}{l}\text { Experimental } \\
\text { field }\end{array}$ & $\begin{array}{l}\text { Examples of multi-step syntheses. Yield } \\
\text { values. Information about the cost and } \\
\text { dangers of the chemical species being used. }\end{array}$ \\
\hline Notions & $\begin{array}{l}\text { Objectives, description and schematization of } \\
\text { multi-step synthesis. Economic feasibility } \\
\text { (cost, impact on mankind and the } \\
\text { environment, principles for green chemistry) } \\
\text { and the consequences of this on the way } \\
\text { reactions are chosen and organized. }\end{array}$ \\
\hline $\begin{array}{l}\text { How can we devise simple strategies for organic } \\
\text { synthesis? }\end{array}$ & $\begin{array}{l}\text { Experimental } \\
\text { field }\end{array}$ \\
\hline matabases (reaction library). Panorama of the \\
motions & $\begin{array}{l}\text { Transforming the main chemical species by } \\
\text { modifying functional groups and carbon } \\
\text { structures. Problems of selectivity. Limits of } \\
\text { this approach for complex syntheses. }\end{array}$ \\
\hline
\end{tabular}

We suggest giving students tasks like : schematizing an organic synthesis using the description of this found in a research paper; choosing between two proposals for the most effective strategy; using the reaction library to estimate yields, and choosing what, a priori, seems to be the best laboratory protocol for synthesis; linking reactions found in the reaction library with steps in a succinct synthetic plan; devising simple syntheses using knowledge of the starting materials or choosing this from a pre-determined pool.

\section{Part 3. What happens during a reaction in organic chemistry? The notion of the reaction mechanism}

This part does not provide a full presentation of all the theoretical tools used in organic chemistry. It merely introduces some starting notions which will be sufficient for establishing polar mechanisms (Table 3; P1, P2). We deliberately limit the place given to the molecular structure and associate this with some thermodynamic tools so as to avoid the harmful effects of an exclusively molecular approach. ${ }^{47}$

Table 3. Content description for part 3 of the curriculum

\begin{tabular}{|l|l|}
\hline $\begin{array}{l}\text { How can the role of acid-base reactions in organic } \\
\text { chemistry be estimated? }\end{array}$ \\
\hline $\begin{array}{l}\text { Experimental } \\
\text { field }\end{array}$ & $\begin{array}{l}\text { Acid-base properties of the main organic } \\
\text { species. }\end{array}$ \\
\hline Notions & $\begin{array}{l}\text { Criterion for considering acid-base reactions } \\
\text { in organic chemistry. Principle of microscopic } \\
\text { reversibility. As there are no pK data, } \\
\text { prediction of relative acid or base strengths } \\
\text { using the model of electronic effects. Limits of } \\
\text { this model: influence of the medium. }\end{array}$ \\
\hline $\begin{array}{l}\text { How can a reaction in organic chemistry be explained or } \\
\text { predicted? }\end{array}$ \\
\hline
\end{tabular}




\begin{tabular}{|l|l|}
\hline $\begin{array}{l}\text { Experimental } \\
\text { field }\end{array}$ & $\begin{array}{l}\text { Examples of organic syntheses. Some } \\
\text { examples of transformations of carbonyl } \\
\text { compounds, carboxylic acid derivatives, alkyl } \\
\text { halides, alcohols and epoxides. }\end{array}$ \\
\hline Notions & $\begin{array}{l}\text { Modifications in the bonds of the substrate's } \\
\text { reactive site. Class of a reaction (addition, } \\
\text { elimination, substitution, rearrangement). } \\
\text { Model of a polar reaction through an } \\
\text { interaction between electron pair donor and } \\
\text { acceptor, leaving group ability ( } \Delta \text { pK } K_{a} \text { rule). } \\
\text { Symbolism of the curved arrow. } \\
\text { Choosing a reaction mechanism which is } \\
\text { consistent with the experimental data. } \\
\text { Predicting a chemical reaction consistent with } \\
\text { the knowledge and criteria available. }\end{array}$ \\
\hline
\end{tabular}

We suggest giving students tasks such as: analyzing the transformation of the substrate in relation to the evolution of the bonds; determining the class of a reaction; describing a reaction mechanism which is given in terms of dissociation / association, as recommended by IUPAC. ${ }^{64}$ The students have to choose between several mechanisms to decide which is the most consistent with the experimental results provided (for example basic hydrolysis of carboxylic ester). They use control knowledge, such as the $\Delta \mathrm{pK}_{\mathrm{a}}$ rule, to do this. Predictive tasks may also be given: predicting a chemical reaction similar to a reaction whose mechanism they have studied; checking the relevance of a prediction or completing a prediction.

\section{Part 4. How can a strategy for organic chemistry be devised? The notions of retrosynthesis and chemoselectivity}

Part 4 is based on concepts which have already been tackled, but goes further on the themes of organic synthesis, particularly the question of the synthesis of a target molecule (table 4) (P1). The aim is not to give a complete course on retrosynthetic analysis, but just a first approach to the subject, with some simple examples (P3). Other selectivity problems appear, with some solutions such as modifying the leaving group ability (using the $\Delta \mathrm{pK}_{\mathrm{a}}$ rule again) (P2).

Table 4. Content description for part 4 of the curriculum

\begin{tabular}{|l|l|}
\hline \multicolumn{2}{|l|}{ How can we use the target molecule as a starting point? } \\
\hline $\begin{array}{l}\text { Experimental } \\
\text { field }\end{array}$ & $\begin{array}{l}\text { Examples of chemical species to be } \\
\text { synthesized, and of multi-step syntheses. } \\
\text { Databases (reaction library). }\end{array}$ \\
\hline Notions & $\begin{array}{l}\text { Retrosynthesis and schematization of this. } \\
\text { Simplification of molecular complexity. } \\
\text { Criteria for choosing a strategic bond. }\end{array}$ \\
$\begin{array}{l}\text { Synthons (donors and acceptors). Synthetic } \\
\text { equivalents and proposals of strategies. }\end{array}$ \\
\hline $\begin{array}{l}\text { How can problems of selectivity in functional group } \\
\text { modifications be managed? }\end{array}$ \\
\hline
\end{tabular}




\begin{tabular}{|l|l|}
\hline $\begin{array}{l}\text { Experimental } \\
\text { field }\end{array}$ & $\begin{array}{l}\text { Examples of selectivity for some common } \\
\text { reagents (oxidizing and reducing reagents). } \\
\text { Examples of multi-step syntheses. }\end{array}$ \\
\hline Notions & $\begin{array}{l}\text { Consequences of the absence of } \\
\text { chemoselectivity in organic synthesis. } \\
\text { Modification of reactivity in a functional group: } \\
\text { protection-deprotection of functional groups, } \\
\text { protective groups (carbonyl compounds, } \\
\text { alcohols...), modification of leaving group } \\
\text { ability (tosylates). }\end{array}$ \\
\hline
\end{tabular}

\section{Part 5. How can the effectiveness of the transformation of a chemical species}

\section{be predicted and altered? Thermodynamic and kinetic approaches}

Part 5 allows students to tackle an in-depth study of the problem of selectivity from a reactional point of view, in order to find solutions and applications for organic synthesis (table 5) (P1). It focuses on more complex notions of thermodynamics and kinetics than in the previous parts (P2), and also on the competition between thermodynamically and kinetically controlled products of a reaction. ${ }^{65}$ In this part, we introduce methods for estimating Gibbs energy change, the group increment method, etc. ${ }^{66,67}$ so as to better link the models up with the experimental field (P2).

Table 5. Content description for part 5 of the curriculum

\begin{tabular}{|l|l|}
\hline $\begin{array}{l}\text { How can the feasibility of on organic reaction be } \\
\text { predicted? } \\
\text { How can this reaction be made possible? }\end{array}$ \\
\hline $\begin{array}{l}\text { Experimental } \\
\text { field }\end{array}$ & $\begin{array}{l}\text { Examples of organic syntheses and some } \\
\text { reactions (eliminations, aromatic } \\
\text { halogenations, hydrocarbon isomerizations, } \\
\text { keto-enol equilibrium, acetalization, } \\
\text { esterification). Formation of strong bonds (Si- } \\
\text { O,P-O, etc.), leaving group ability (tosylate, } \\
\text { etc.). Influence of the experimental conditions } \\
\text { (solvent, T, P). }\end{array}$ \\
\hline Notions & $\begin{array}{l}\text { Method for estimating Gibbs energy change. } \\
\text { Group increment method; deviations } \\
\text { (aromaticity, conjugation...). Thermodynamic } \\
\text { selectivity. Applications in organic synthesis } \\
\text { (stabilization of the final state, equilibrium } \\
\text { displacement). }\end{array}$ \\
\hline $\begin{array}{l}\text { How can the } \\
\text { How can this reaction be speeded up or blocked? }\end{array}$ \\
\hline $\begin{array}{l}\text { Experimental } \\
\text { field }\end{array}$ & $\begin{array}{l}\text { Examples of organic syntheses and some } \\
\text { reactions (substitutions of substituted } \\
\text { benzenes, anionic oxy-Cope rearrangement, } \\
\text { enolate alkylations...). Influence } \\
\text { experimental conditions (solvent, cryptand, T, } \\
\text { P). Catalysts (acid, enzymatic...). }\end{array}$ \\
\hline
\end{tabular}




\begin{tabular}{|l|l|}
\hline Notions & $\begin{array}{l}\text { Rate-limiting step, Eyring equation, activation } \\
\text { parameters, the Hammond postulate, reaction } \\
\text { intermediates. Activation by destabilizing } \\
\text { reagents or by stabilizing the transition state. } \\
\text { Catalysis. Kinetic selectivity. }\end{array}$ \\
\hline $\begin{array}{l}\text { How can the thermodynamically or kinetically controlled } \\
\text { product be selected if there is competition? }\end{array}$ \\
\hline $\begin{array}{l}\text { Experimental } \\
\text { field }\end{array}$ & $\begin{array}{l}\text { Examples of organic syntheses and some } \\
\text { reactions (hydrohalogenation of alkenes, } \\
\text { trapping the kinetic enolates by forming silyl } \\
\text { enol ether, etc.). Influence of parameters. }\end{array}$ \\
\hline Notions & $\begin{array}{l}\text { Thermodynamic and kinetic controls. Parallel } \\
\text { between time and temperature. Selectivity. }\end{array}$ \\
\hline
\end{tabular}

\section{Part 6. How can the stereochemistry of a chemical species transformation be controlled? Notions of stereoselectivity and stereospecificity}

This final part focuses on the problems of stereoselectivity with notions of stereochemistry and the study of mechanisms which require students to use most of the theoretical elements introduced in previous parts $\left(S_{N} 2, S_{N} 1, E 1, E 2\right.$ mechanisms, etc.) (table 6 ). This does not mean that students were not already familiar with some elements of stereochemistry from General Chemistry courses or previous teaching. But students did not need stereochemical models in order to answer all the questions tackled in the previous parts. We considered it would be detrimental to learning for students to have to cope with all the difficulties of the curriculum right from the start (P1).

Table 6. Content description for part 6 of the curriculum

\begin{tabular}{|l|l|}
\hline $\begin{array}{l}\text { How can the tridimensional structure of an organic } \\
\text { species be determined? }\end{array}$ \\
\hline $\begin{array}{l}\text { Experimental } \\
\text { field }\end{array}$ & $\begin{array}{l}\text { Experimental results concerning } \\
\text { chromatography on chiral stationary phases, } \\
\text { polarimetry, spectroscopy. Resolution of a } \\
\text { racemate. }\end{array}$ \\
\hline Notions & $\begin{array}{l}\text { Relationships between tridimensional } \\
\text { structures and physical properties. } \\
\text { Stereochemical models (VSEPR theory, } \\
\text { molecular orbitals). } \\
\text { Stereoisomerism. Conformational analysis. }\end{array}$ \\
\hline $\begin{array}{l}\text { How can stereochemistry be controlled during a } \\
\text { transformation of chemical species? }\end{array}$ \\
\hline $\begin{array}{l}\text { Experimental } \\
\text { field }\end{array}$ & $\begin{array}{l}\text { Examples of organic syntheses and some } \\
\text { stereoselective reactions (halogenation of } \\
\text { alkenes, reactions of carbonyl compounds } \\
\text { and alkyl halides, Diels-Alder reaction, etc.). } \\
\text { Molecular recognition, chiral catalysts, } \\
\text { stereoselective reagents. }\end{array}$ \\
\hline
\end{tabular}




\begin{tabular}{|l|l|}
\hline Notions & $\begin{array}{l}\text { Models for explaining stereoselectivity (Cram, } \\
\text { steric hindrance, orbital interactions in the } \\
\text { initial state or transition state). } S_{N} 2, S_{N} 1, E 1, \\
E 2, A_{N} \text { and } A_{E} \text { mechanisms. }\end{array}$ \\
\hline
\end{tabular}

\section{Conclusion}

As a result of existing studies, we have drawn up a new organic chemistry curriculum for the first two years in higher education courses. This covers the overall structure of the curriculum as well as the actual tasks given to the students. However this new and very different curriculum may be difficult to implement. Indeed, professors have little leeway because of the weight of the institution, exams and teaching habits; this is also due to the shortage of textbooks and alternative resources. ${ }^{44,51,68,69}$ But already our arguments have led some teachers to make considerable changes to their classes (ongoing research). And some of our suggestions now appear in the new national Grade 12 physics and chemistry curriculum $^{70}$, and in the new national curriculum of preparatory classes for selective postgraduate schools ('grandes écoles'). ${ }^{71}$ So such a curriculum is a real challenge for the chemistry education community. After the two epistemological changes described by Loumouamou $^{47}$, the history of organic chemistry needs to move on once again, but this time, it must do so in the field of teaching and learning.

\section{Acknowledgments}

We would like to thank Judith Barnoin for translating this article.

\section{Literature cited}

1. Kingsbury, C. A. J. Chem. Educ. 1986, 63, 315-317.

2. Bradley, A. Z.; Ulrich, S. M.; Maitland, J. Jr.; Jones, S. M. J. Chem. Educ. 2002, 79, 514-519.

3. Murov, S. J. Chem. Educ. 2007, 84, 1224.

4. Esteb, J. J.; Magers, J. R.; McNulty, L.; Wilson, A. M. J. Chem. Educ. 2006, 83, 1807-1808.

5. Teixeira, J.; Holman, R. W. J. Chem. Educ. 2008, 85, 88-89.

6. Hagen, J. P. J. Chem. Educ. 1988, 65, 620.

7. Erdik, E. J. Chem. Educ. 2005, 82, 1325-1326.

8. Browne, L. M.; Blackburn, E. V. J. Chem. Educ. 1999, 76, 1104-1107.

9. Black, A. E.; Deci, E. L. Sci. Ed. 2000, 84, 740-756.

10. Bradley, A. Z.; Ulrich, S. M.; Jones Jr., M.; Jones, S. M. J. Chem. Educ. 2002, 79, 514-519.

11. Cooley, J. H. J. Chem. Educ. 1991, 68, 503-504.

12. De Jesus, K.; J. Chem. Educ. 1995, 72, 224-226.

13. Hagen, J. P. J. Chem. Educ. 2000, 77, 1441-1444.

14. Horowitz, G.; Schwartz, G. J. Chem. Educ. 2004, 81, 1136-1139.

15. Libby, R. D. J. Chem. Educ. 1995, 72, 626-631.

16. Platt, T.; Roth, V.; Kampmeier, J. A. Chem. Educ. Res. Pract. 2008, 9, 144-148.

17. Vosburg, D. A. J. Chem. Educ. 2008, 85, 1519-1523. 
18. Zoller, U.; Pushkin, D. Chem. Educ. Res. Pract. 2007, 8, 153-171.

19. Tien, L. T.; Roth, V.; Kampmeier, J. A. J. Res. Sci. Teach. 2002, 39, 606-632.

20. Huddle, P. A. J. Chem. Educ. 2000, 77, 1154-1157.

21. Green, G.; Rollnick, M. J. Chem. Educ. 2006, 83, 1376-1381.

22. Ellis, J. W. J. Chem. Educ. 1994, 71, 399-403.

23. Goldish, D. M. J. Chem. Educ. 1988, 65, 603-604.

24. Forbes, D. C. J. Chem. Educ. 2004, 81, 975-976.

25. Reingold, I. D. J. Chem. Educ. 2001, 78, 869-871.

26. Smith, M. B. J. Chem. Educ. 1990, 67, 848-856.

27. Agrebi, S. De la représentation symbolique au langage lors de l'apprentissage des mécanismes en chimie organique dans l'enseignement supérieur. Ph.D. Thesis, Universités Lyon 2 et de Tunis, Lyon \& Tunis, 2004.

28. Ferguson, R.; Bodner, G. M. Chem. Educ. Res. Pract. 2008, 9, 102-113.

29. Friesen, J. B. J. Chem. Educ. 2008, 85, 1515-1518.

30. Weeks, D. P. Pushing electrons: a guide for students of organic chemistry. Third ed., Saunders College Publishing: U.S., 1998.

31. Wentland, S. S. J. Chem. Educ. 1994, 71, 3-8.

32. Gravert, D. J. J. Chem. Educ. 2006, 83, 898-901.

33. Grove, N. P.; Hershberger, J. W.; Bretz, S. L. Chem. Educ. Res. Pract. 2008, 9, $157-$ 162.

34. Minter, D. E.; Reinecke, M. G. J. Chem. Educ. 1985, 62, 77-79.

35. Sartoris, N. E. J. Chem. Educ. 1992, 69, 750-752.

36. Libby, R. D. J. Chem. Educ. 1991, 68, 634-637.

37. Karty, J. M.; Gooch, G.; Bowman, B. G. J. Chem. Educ. 2007, 84, 1209-1216.

38. Cracolice, M. S.; Deming, J. C.; Ehlert, B. J. Chem. Educ. 2008, 85, 873-878.

39. Ilich, P.-P.; Rickertsen, L. S.; Becker, E. J. Chem. Educ. 2006, 83, 1681-1685.

40. Taagepera, M.; Noori, S. J. Chem. Educ. 2000, 77, 1224-1229.

41. Bhattacharyya, G.; Bodner, G. M. J. Chem. Educ. 2005, 82, 1402-1407.

42. Scudder, P. H. J. Chem. Educ. 1997, 74, 777-781.

43. Straumanis, A. Organic chemistry. A guided inquiry. $2^{\text {nd }}$ edition, Houghton Mifflin: Boston - New-York, 2008.

44. Lafarge, D. Didactical analysis of teaching and learning in introductory organic chemistry: towards an overall restructuring of contents. Ph.D. Thesis, Université Blaise Pascal, Clermont-Ferrand, 2010. http://tel.archives-ouvertes.fr/tel-00578419 (accessed Aug 2012).

45. Johnson, A. W. J. Chem. Educ. 1990, 67, 299-303.

46. Terrien, M. Contribution à l'étude des échanges entre la recherche et l'enseignement supérieur (chimie). Ph.D. Thesis, Université d'Angers, Angers, 1998.

47. Loumouamou, A. Contribution à la transposition didactique en chimie organique. Ph.D. Thesis, Université Joseph Fourier, Grenoble, 1998.

48. Bécu-Robinault, K. ASTER 2007, 45, 165-188.

49. Anderson, T. L.; Bodner, G. M. Chem. Educ. Res. Pract. 2008, 9, 93-101. 
50. Ladhams Zieba, M. Teaching and learning about reaction mechanisms in organic chemistry. Ph.D. Thesis, University of Western Australia, Perth, 2004.

51. Bucat, R. Chem. Educ. Res. Pract. 2004, 5, 215-228.

52. Stewart, J.; Rudolph, J. L. Sci. Ed. 2001, 85, 207-222.

53. Almeida, C. A.; Liotta, L. J. J. Chem. Educ. 2005, 82, 1794-1799.

54. Gallagher, G. J.; Adams, D. L. J. Chem. Educ. 2002, 79, 1368-1371.

55. Shibley Jr., I. A.; Milakofsky, L. K.; Nicotera, C. L. J. Chem. Educ. 2001, 78, 50-53.

56. Bhattacharyya, G. Chem. Educ. Res. Pract. 2008, 9, 84-92.

57. Raker, J. R.; Towns, M. H. Chem. Educ. Res. Pract. 2012, 13, 179-185.

58. Raker, J. R.; Towns, M. H. Chem. Educ. Res. Pract. 2012, 13, 277-285.

59. Talanquer, V.; Pollard, J. Raker, J. R.; Towns, M. H. Chem. Educ. Res. Pract. 2010, 11, 74-83.

60. Nicolaou, K. C.; Sorensen, E. J.; Winssinger, N. J. Chem. Educ. 1998, 75, 12251258.

61. Walliser, B. Systèmes et modèles. Introduction critique à l'analyse des systèmes. Editions du Seuil: Paris, 1977.

62. Lemeignan, G.; Weil-Barais, A. Construire des concepts en physique. Hachette: Paris, 1993.

63. Martinand, J.-L. Apprendre à modéliser. In Changement conceptuel et apprentissage des sciences. Recherches et pratiques; Toussaint, R. M. J., Ed.; Les éditions logiques: Québec, 2002; pp 47-68.

64. Guthrie, R. D. Pure \& Appl. Chem. 1989, 61, 23-56.

65. Jullien, L.; Proust, A.; Le Menn, J.-C. J. Chem. Educ. 1998, 75, 194-199.

66. Vogel, P. Chimie organique. Méthodes et modèles. De Boeck Université: Paris Bruxelles, 1997.

67. Anslyn, E. V.; Dougherty, D. A. Modern physical organic chemistry. University Science Books: U.S., 2006.

68. Farré, A. S.; Lorenzo, M. G. Chem. Educ. Res. Pract. 2009, 10, 176-184.

69. Holme, T.; Bretz, S. L.; Cooper, M.; Lewis, J.; Paek, P.; Pienta, N.; Stacy, A.; Stevens, R.; Towns, M. Chem. Educ. Res. Pract. 2010, 11, 92-97.

70. Ministère de l'Éducation Nationale, Enseignement spécifique et de spécialité de physique-chimie de la série scientifique-classe terminale. Bulletin officiel spécial $n^{\circ} 8$ du 13 octobre 2011.

71. Ministère de l'Éducation Nationale, Programmes de la classe préparatoire scientifique Physique, chimie et sciences de l'ingénieur (PCSI) et programme de sciences industrielles de l'ingénieur de la classe Physique et sciences de l'ingénieur (PSI). Bulletin officiel spécial n`3 du 30 mai 2013. 